\title{
Modelling of Construction Products and Services for Effective Productisation
}

\author{
JANNE HARKONEN \\ University of Oulu, Finland \\ janne.harkonen@oulu.fi \\ ARTO TOLONEN \\ University of Oulu, Finland \\ arto.tolonen@oulu.fi \\ HARRI HAAPASALO \\ University of Oulu, Finland \\ harri.haapasalo@oulu.fi
}

Modelling of construction products and services has major importance for effective productisation of construction companies' offering. Productisation refers to the process of analysing customer needs and defining the offering both commercially and technically so that the efficiency of the productisation can be repeated and the offering is possible to understand. Productised offering is possible to be sold, delivered and invoiced while the effectiveness of construction activities can be maximised. The purpose of this paper is to demonstrate the importance of modelling construction products and services to enable effective productisation of the offering. The study is realised as a combination of a literature review, analysing apartments and houses available by real estate search engines, and analysing constructors' descriptions on method of construction. The study applies the product structure concept. The results include presenting an example of modelling construction offering both as a product and as a service in a manner that enables effective productisation. The findings support productisation to have a role in systematising and tangibilising the construction offering and indicates commercial and technical modelling to support maximising the effectiveness of construction activities. The results support increasing the understanding over modelling construction offering and commercial productisation of the offering. The productisation differences of construction offering modelled as a product and as a service are on the side of technical implementation. Construction companies and managers can benefit of the results while considering modelling their offering and the related productisation logic.

Key words: productisation, commercial product portfolio, technical product portfolio, management, product portfolio management, construction products, construction services

https://doi.org/10.26493/1854-4231.13.335-353

MANAGEMENT 13 (4): 335-353 


\section{Introduction}

Construction offering has typically been viewed as a product in the form of completed facility that is a result of a production process, but construction is also provided as service products (Maloney 2002). In general products and services are necessary to understand and maintain both on the commercial side including the understanding of sellable items and in terms of the technical structure, and technical interrelations. Hence, a level of modelling is necessary.

The discussion on modelling in the construction context has a specific focus. For example, modelling of buildings are discussed to give architecture, engineering, and construction professionals insights and tools for the more efficient planning, designing, constructing, and for managing buildings. The discussion under the Building Information Modelling (вім) covers construction and construction process related information in digital format to cover the entire lifecycle (Azhar et al. 2008; Cerovsek 2011). However, in a way Bıм could be seen as a new process to provide more than computer aided design (CAD) (Azhar et al. 2008, 4). The construction related modelling has evolved from building description system (Eastman 1976), building product model (Björk 1989), and generic building modelling (Eastman and Siabiris 1995) to the modern вiм. However, вiм does not clearly consider modelling from the perspective of product structure, which without a doubt could be built in. Product structure refers to 'an organised hierarchical collection of technical objects that are linked via "part-of" relationships' (Pinquié et al. 2015). This even if the importance of adapting the information model to the building process and product structure has been highlighted (Olofsson, Stehn, and Cassel-Enqvist 2004). In fact the lack of product structure has been argued as the missing link of the вIм approach (Boton et al. 2016). Product structure would further support product configuration and modularity considerations.

Product configuration is rather scarcely discussed in the construction context involving construction product families and architectures (Hvam, Mortensen, and Riis 2008). Prefabrication is used in construction, but it is seen unable to provide satisfactory results as the activities are rather wasteful (Tam et al. 2007). The industrialisation of housing production have learned from other manufacturing processes and have gained benefits by managing the entire production system from supply-chain management to factory production to sales and on-site activities with adequate balance of standardisation and flexibility (Gann 1996). In fact, the off-site construction is seen to have paramount significance for the efficiency (Taylor 2010). 
Nevertheless, product configurability has been considered in the construction context with product family type decomposition that is opened to system and subsystem levels, and modules and components (Jensen, Lidelöw, and Olofsson 2015). Configurability of construction service products has not been discussed. Jensen, Lidelöw, and Olofsson (2015) have also noticed that construction product configuration should be based on a modular architecture. Nevertheless, according to Jensen, Olofsson, and Johnsson (2012) modules more complex than building elements are rare in construction. However, the portfolio perspective and commercial and technical portfolios in this context are yet to be considered.

The modularity has been discussed in the construction context also to a rather moderate extent (Björnfot and Stehn 2007). In construction, product modularity is affected by the degree of component independence and the degree of interface standardisation (Voordijk, Meijboom, and de Haan 2006). If considering process modularity in the construction context, the used production and manufacturing techniques have great significance (Voordijk, Meijboom, and de Haan 2006). Modular construction is, for example, considered for modules for heating, ventilating and air conditioning (Pasquire and Connolly 2002). The modularity is more considered in the off-site building discussion, where some scepticism for complete modular buildings have been presented (Pan, Gibb, and Dainty 2007). Some define offsite in construction context as the manufacture and preassembly of components, elements or modules before installation in final location (Goodier and Gibb 2007). There is also discussion under the terms of modern methods of construction that cover off-site manufacturing, prefabrication and off-site production (Nadim and Goulding 2010). However, rather little discussion exists on construction modularity compared to other industrial sectors (Antonio, Yam, and Tang 2007; Pandremenos et al. 2009). The product portfolios have neither been discussed in the construction context to include the commercial and technical considerations. Furthermore, the configurability and modularity have not been clearly discussed together in this context.

Productisation also relates to the management of products and services and the commercial and technical product portfolios (Harkonen, Tolonen, and Haapasalo 2018; Tolonen et al. 2018). The concept of productisation relates to a process of analysing a need, defining and combining suitable elements, into a product-like defined set of deliverables (Harkonen, Haapasalo, and Hanninen 2015). Productisation also plays a role managing the service offering (Harko- 
nen, Tolonen, and Haapasalo 2017). Productisation simply addresses the inefficiency involved in production of products and services (Jaakkola 2011; Valminen and Toivonen 2012). The relationship of modelling of products and services and the concept of productisation has been discussed to some extent (Harkonen, Tolonen, and Haapasalo 2018; Tolonen et al. 2018), but the previous discussion has been particularly limited in the construction context.

The above discussion can be condensed into the following research question:

$\mathrm{RQ}$ How can construction products and services be modelled for effective productisation?

The above research question is attempted to answer by the means of an extensive literature review and by providing an example of modelling manufacturing products and services.

\section{Literature Review}

PRODUCT PORTFOLIO MANAGEMENT

A company's offering can be considered along the lines of product structure concept by considering product families and product variants (Pavlic et al. 2004). Product structure concepts supports decision making and can lead to cost advantage solutions (Ripperda and Krause 2015). The modular product structures can also reduce the variety within a company while offering improved variety to the external customer (Krause et al. 2014). From the customer perspective, a configurable product can be composed according to the needs of a customer based on a generic product structure (Pavlic et al. 2004). Customer satisfaction, an imperative factor for successful business (Vukasovic and Mikulic 2014) can be supported by configurable product and service offering. Also, multiple different views can be considered for the product structure to benefit various stakeholders (Kropsu-Vehkapera and Haapasalo 2011).

The product structure concept can be utilised in the product portfolio management context by considering the commercial and technical portfolios (figure 1). This type of division has been considered for physical products (Tolonen, Harkonen, and Haapsalo 2014; Tolonen 2016; Kokkonen 2017; Mustonen 2017) and for services (Harkonen, Tolonen, and Haapasalo 2017; Harkonen, Tolonen, and Haapasalo 2018; Mustonen 2017). The commercial perspective has a customer focus and is familiar with marketing, sales, and product management (Tolonen, Harkonen, and Haapsalo 2014). Commercial productisation for sales offers, contracts, orders, deliveries and invoices 
takes place on the side of commercial portfolio (Tolonen et al. 2018). The technical perspective is understood more deeply by the product/service development, engineering, testing, purchasing, logistics, and suppliers (Tolonen, Harkonen, and Haapsalo 2014). Technical productisation for product development, supply management, manufacturing, and service processes takes place on the side of technical portfolio (Tolonen et al. 2018).

The commercial product and service portfolios have a hierarchy that can be formed for example to consist of product families, product configurations and sales items (Harkonen, Tolonen, and Haapasalo 2017; 2018; Kokkonen 2017; Tolonen, Harkonen, and Haapsalo 2014; Tolonen et al. 2018; Tolonen 2016). There are no differences in the logic of commercial portfolio of products or services (Harkonen, Tolonen, and Haapasalo 2018; Tolonen et al. 2018). The difference between physical products and service products lies in the technical implementation. When considered as products, the technical product portfolio consists of all hierarchies of platforms, assemblies, sub-assemblies, components and materials that are used for creating the product offering (Harkonen, Tolonen, and Haapasalo 2018; Tolonen, Harkonen, and Haapsalo 2014; 2018; Tolonen 2016). Should the offering be considered as a service, the technical portfolio consist of service processes, sub-service processes, resources, parts and materials that are needed for creating the service offering (Harkonen, Tolonen, and Haapasalo 2017; 2018; Tolonen et al. 2018). Regardless of the differences on the technical side, common to products and services is that should there be any changes to the product within the structure it will have impacts both in a commercial sense, and in a technical sense (Orfi, Terpenny, and Asli 2011). Therefore, when considering productisation in the context of commercial and technical portfolios, the focus of productisation is primarily on the commercial portfolio once the technical side have been modelled and involves considerations surrounding product configurations and sales items (Harkonen, Tolonen, and Haapasalo 2018).

The idea of product portfolio management relates to the need to monitor and react to the behaviour of products and services both in the markets and inside the company to maximise the effectiveness (Cooper, Edgett, and Kleinschmidt 1997). This applies vertically over the product structure, but also horizontally over the lifecycle (Tolonen 2016). The horizontal considerations can for example use the division as illustrated by figure 2 . Construction projects being costly and often exceeding the planned scenario (Peleskei et al. 


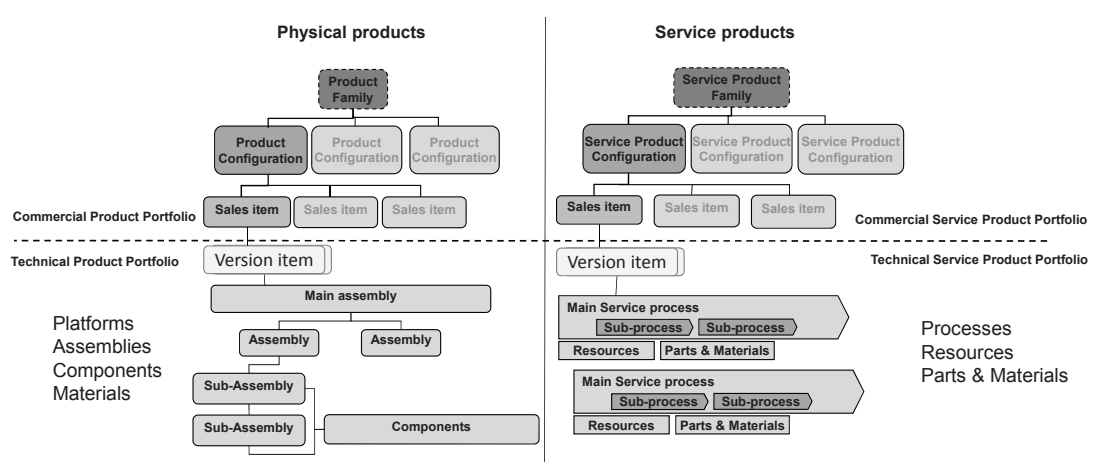

FIGURE 1 Product Structure Concept in the Portfolio Management Context: Physical Products vs. Service Products (adapted from Harkonen, Tolonen, and Haapasalo 2018, 4)

FIGURE 2

Product Portfolio Management Considerations Horizontally over Life-Cycle (adapted from Tolonen et al. 2015a, 472)

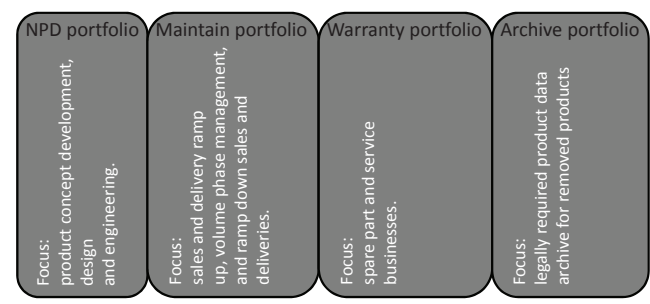

2015) can be addressed by the potential for effectiveness maximisation enabled by the effectiveness of productising the construction offering. Also, while introducing of new products on the market is important (Vukasovic and Zidar 2014), the portfolio must be maintained to avoid unnecessary accumulation of products within a certain life-cycle stage.

\section{Research Process}

The study is realised as a combination of a literature review, analysing apartments and houses available by real estate search engines, and analysing constructors' descriptions on method of construction. A hypothetical example of modelling construction offering is created based on real estate search engine results and the analysed descriptions on method of construction. The created example of modelling construction offering is done so that the offering is presented both as a product and as a service. The study applies the product structure concept. The construction offering is modelled to include both, the commercial and the technical product portfolio. 
The literature review aims to provide relevant understanding over the importance of modelling products and services, productisation, and product portfolio management. The construction industry specific context is touched upon to a necessary level. The literature review is realised by conducting key word searches and analysing the relevant content. Apartment and house layouts are analysed by utilising real estate search engines of Etuovi.com and Rightmove.co.uk to obtain understanding over what type of elements different size houses and apartments constitute. The obtained understanding is utilised to model example commercial portfolios. The technical portfolios are considered to the extent possible by publically available material. Constructors' descriptions on method of construction are particularly utilised for providing an example how the technical portfolio can be modelled when the offering is provided as a service. The constructors' descriptions on method of construction have been obtained from Finnish construction companies' information on newly built apartment projects. The construction companies whose descriptions of method of construction have been analysed include Rakennusteho, Hartela, yıт, Lehto group, and Lapti. The concept of productisation is demonstrated in the context of modelling product and service portfolios in the construction setting. The apartment and house layouts, and the analysed documentation allowed gaining a general understanding of the construction offering. The proposed modelling have not been reviewed with construction professionals. None of the construction companies whose descriptions of method of construction are analysed have clearly modelled the commercial offering. The extent of different actors having modelled their technical portfolio is not possible to analyse within the boundaries of this study.

\section{Results}

The construction companies have typically not clearly modelled the commercial side of their offering. Also, the pricing of the offering and the controllability of the offering are very much company specific. Modelling would help these considerations and support minimising wasteful activities and maximising the effectiveness of construction practices. The offering life-cycle stages would also be possible to address with a modelled offering.

As a major result of this study, an example of commercial portfolio is modelled for construction offering both as a product and as a service. The commercial product portfolio consists of seven product families of Apartments, Detached houses, Semi-detached houses,

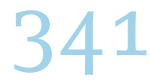




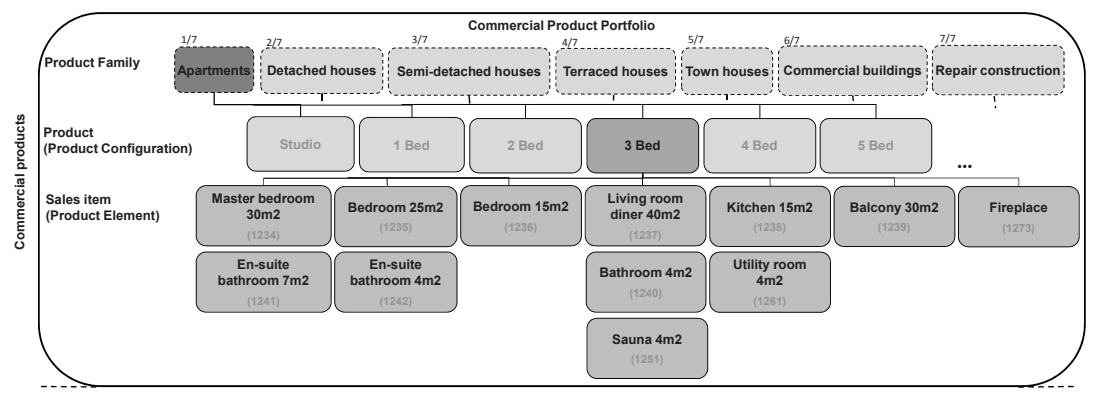

FIgure 3 Commercial Product Portfolio for Construction Offering Modelled as a Product

Town houses, Commercial buildings, and repair construction (figure 3).

In the example the product family of Apartments is further divided into Product configurations based on the number of bedrooms. The product configuration is the product that the customer buys. In the example the product configuration consisting of three bedrooms is further divided into individual sales items, the product elements. Each of the sales items can be priced individually, and in the case of construction products also sold separately until the point of locking the product configuration. The 148 square meter, three bedroom apartment consists of three different size bedrooms, two of which equipped with en-suite bathrooms. The living room diner is a space consisting of the living room space and the dining area. The living room diner has access to a bathroom and a sauna that are linked. The modelled apartment has a separate kitchen that links to a utility room. The apartment also has a balcony and a fireplace.

Figure 4 illustrates the modelled commercial portfolio for the construction offering as a service and reveals how there are no differences in the modelling on the commercial side. The main difference on the commercial side is whether talking about products or services.

The presented example of the commercial product family of Apartments was modelled based on the analysed apartment layouts and the elements the apartments constitute as presented by the real estate search engines. The product configuration of three bedrooms is hypothetical based on the elements the apartments constitute. The sales items are those elements the example apartment constitutes. Each of the product families can be modelled by using the same logic so that each product family constitutes a number of product configurations. The sales items would constitute of the options possible for 


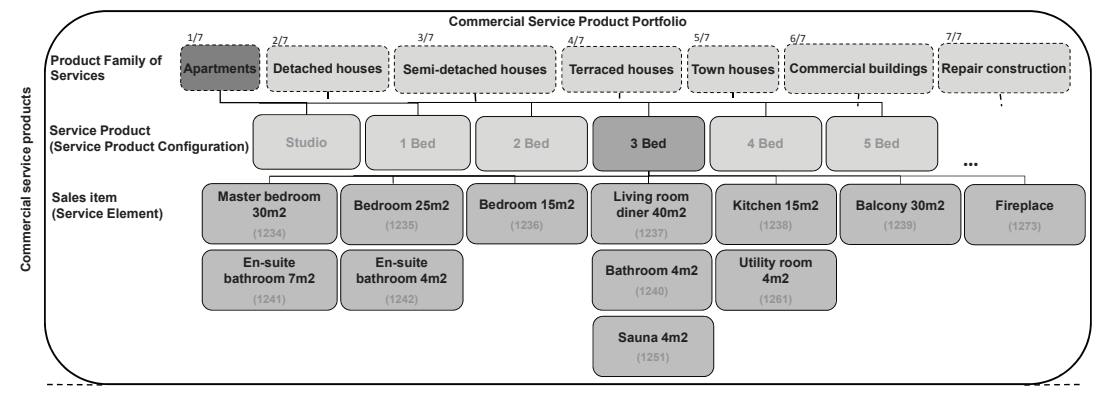

FIGURE 4 Commercial Product Portfolio for Construction Offering Modelled as a Service

customers, those that the company is willing to provide. The service product configurations of the product families of commercial buildings and repair construction would follow a slightly different logic to that of residential buildings. Also the sales items for these product families can be different.

The modelled commercial portfolio allows selling the construction offering so that there is no need to re-consider everything from scratch every time, but the customer and the sales can together select a suitable product family and configure the needed offering based on configure-to-order methods, instead of engineering-to-order. A construction actor can have pre-thought options it is willing to provide, and if customisation is offered the logic to do it in a manageable manner does exist. Modelling of the construction offering also supports pricing considerations as each of the sales items is known. Once the construction offering is modelled, there will be data available to support life-cycle activities involving the offering, for example for maintenance or repair purposes. Also the warranty period is better supported. As a result the same construction offering can be provided a number of times, and new products and services productised in a manageable fashion.

The technical product portfolio of construction offering modelled as a product is based on modules that represent a set of platforms, assemblies, components and materials (figure 5). Each of the modules links to related sales items and product configurations. The modules represent elements possible so that a variety of allowed options are represented. The variety can be set based on company motivations and willingness to provide different modules. Each of the modules presents one way of providing the module, and any differences are represented by version numbers. The coding of the sales items and the corresponding version items support data manage- 


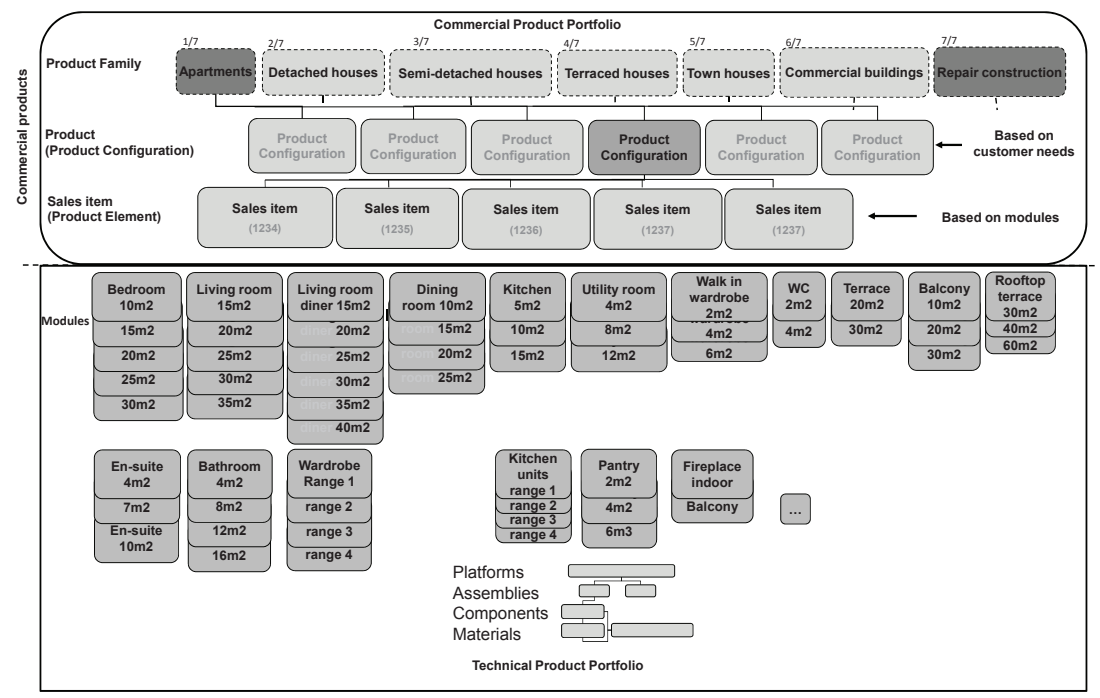

FIgURE 5 Commercial and Technical Product Portfolio of Construction Offering Modelled as a Product: Technical Portfolio Based on Modules

ment and relate to the configurability of the commercial portfolio and the modularity of the technical portfolio.

The technical product portfolio of construction offering modelled as a service is based on platforms that represent the methods of construction (figure 6). Constructors' descriptions on method of construction are utilised for considering the necessary platforms. The platforms link to corresponding service processes and to related sales items and service product configurations. The platforms represent the methods available for construction. Each of the platform represent the use of the method in a certain way and any differences are presented by version numbers. The service processes consist of a combination of the available methods represented by the platforms so that methods with suitable version numbers are linked to corresponding processes. The coding of the sales items and the corresponding version items support data management and relate to the configurability of the commercial portfolio and the modularity of the technical portfolio in the same manner as if modelled as a product. The main difference when modelled as a service is that the technical portfolio consists of processes and instead of pre-defined modules methods of construction are relevant. In both ways of modelling the technical portfolio is modular and the commercial portfolio is configurable. The technical portfolio when modelled as a service can 


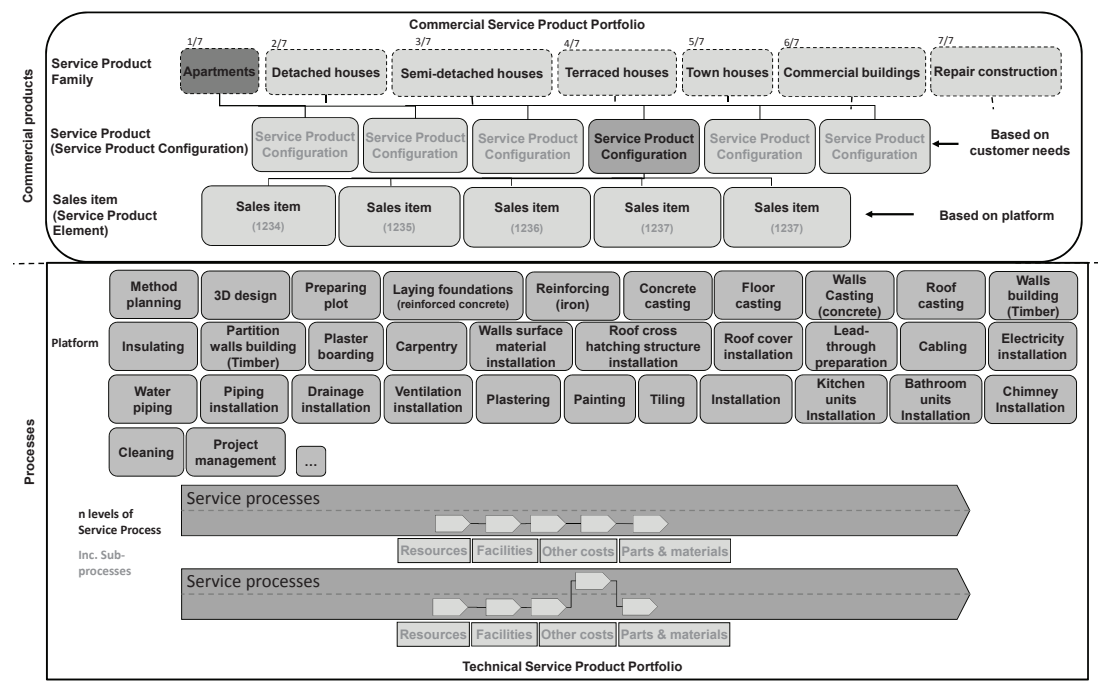

Figure 6 Commercial and Technical Product Portfolio of Construction Offering Modelled as a Service: Technical Portfolio Based on Platforms

consist of a number of process levels that consist of related subprocesses, necessary labour, parts and material, facilities, and such. The number of process levels can for example link to the number of levels of bills of materials to ensure ease of compatibility. The applied modelling can provide clarity so that similar things are always considered the same way.

The construction offering can be modelled both as a product and as a service and presented generically as in figure 7 . It is the level of detail that is reduced. Modelling each individual product or service in detail requires using an adequate system that allows also visually viewing the linkages. For both, modelled as a product or as a service, the commercial portfolio can be broken down to product families that can be further broken down to product configurations, and related sales items that are further connected to corresponding technical version items. The commercial sales items for services can either be exactly the same as for products, or can be the methods that constitute the platforms in case of services. If this was the case the sales items could be for example insulating or plastering. Version items would then be then certain type of insulating or plastering. If the service sales item was to be for example 15 square meter kitchen, then the processes would consist of a combination of necessary platforms organised as a set of processes. The service processes can be either internal only without visibility by customers, or with 


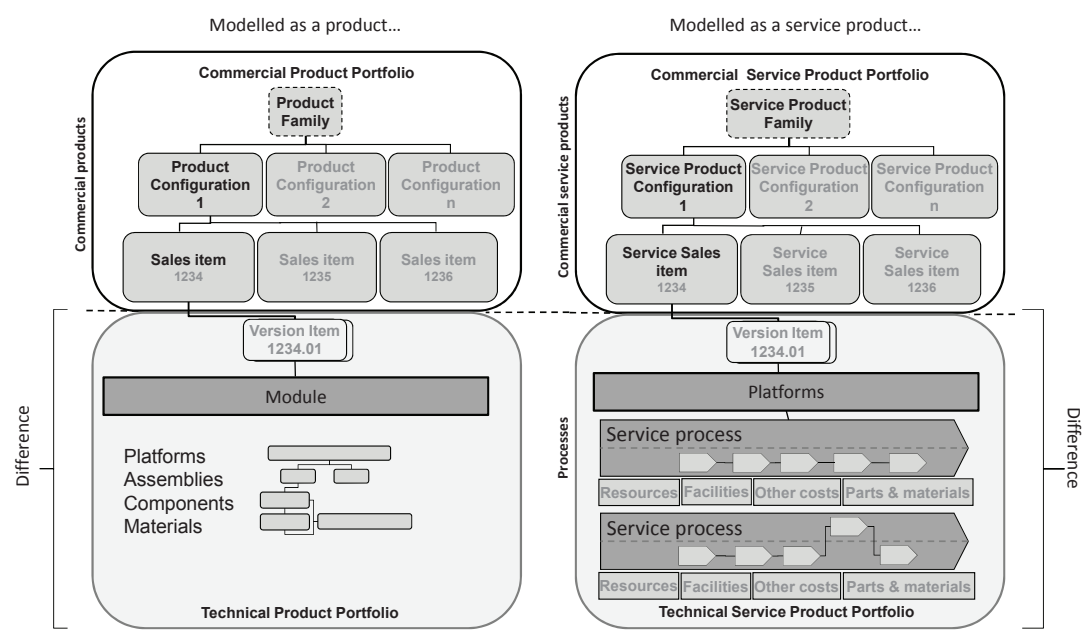

FIGURE 7 The Modelled Construction Offering as Commercial and Technical Product Portfolios Both as a Product and as a Service

customer involvement. All the service processes are linked to necessary resources, facilities, parts and materials.

The modelling of construction services enables to analyse the formation of the product or service prices in a rather detailed level. This may also allow considering different pricing mechanisms.

Finding 1. Modelling of construction products and services s according to commercial and technical portfolios provides the necessary platform for analysing the formation of construction products and services to enable maximising the effectiveness of construction activities.

\section{Discussion}

Modelling of construction products and services appears to provide the necessary frame for effective commercial and technical productisation of construction offering. Modelling of the offering is necessary to have the needed frame for productisation. Once the construction offering has been modelled, productisation can focus on the commercial side of the product or service portfolio.

The primary focus of productisation is on the product/service configurations should there be needs to provide something new the existing portfolio does not directly contain. The new product/service configurations are mainly created based on the existing sales items that the company knows and understands the costs. This way there 
are no need of carry out productisation activities on the technical side of the portfolio. Ideally customer needs can be met by product/service product configurations, or individual sales items. The company's existing product/service product portfolio can be complemented by developing additional product/service variants by creating new sales items. It is, however, important to understand that each new sales item involves new version items due to changes in technical implementation. In case the existing modules (construction offering as a product), and platforms (construction offering as a service) do not provide the necessary possibilities for new products or services, the introduction of new modules or platforms may need to be considered. However, in order to maintain the portfolio balance also horizontally, new products and services cannot be added in an uncontrolled fashion, but some products/services may need to move along the horizontal portfolio stages. In case a company has not modelled its construction offering before, the productisation can involve the modelling activities.

Modelling of construction products/services can provide necessary clarity for effective management of the offering, aside providing frame for effective productisation. Also the repeatability of construction products/services is supported. The manufacturing offering related life-cycle and data considerations may also become more tangible along the modelling when using the product structure concept in the context of commercial and technical product/service product portfolios.

Finding 2. Modelling construction offering by using the product structure concept allows a manageable logic for productising construction offering as products or services.

The results indicate that construction products and services can be modelled to some extent, even without the direct company involvement. Particularly the commercial portfolio can be modelled rather well with the help of public information. The positioning of the construction company in the value chain can impact whether the technical portfolio is to be modelled as a product or as a service. Overall, modelling construction offering can support meeting the purpose of product portfolio management of monitoring and reacting to the behaviour of products/services in the company and in the markets to support maximising the effectiveness of construction activities and enable optimal overall company results. Portfolio management enables focusing on providing products and services that are profitable and in line with the company strategy. 
The scientific implications include highlighting the construction offering as products and services in the light of the product structure concept, supporting the understanding in related literature (Maloney 2002; Pinquié et al. 2015). The findings support the linking of product structure and information model, hence supporting previous literature (Olofsson, Stehn, and Cassel-Enqvist 2004). This study provides new to the previous literature by emphasising the support product structure can provide for configurability and modularity considerations in the construction industry. Support is provided particularly for Boton et al. (2016) who highlight how construction related modelling might be lacking the product structure perspective by this study proving a practical example of its utilisation.

New perspectives are provided for product configuration related construction discussion (Gann 1996; Jensen, Olofsson, and Johnsson 2012; Jensen, Lidelöw, and Olofsson 2015; Tam et al. 2007; Taylor 2010) by providing an example of how the construction related commercial portfolio can be formed by using the product structure concept. The commercial product/service portfolio is configurable.

New perspectives are also provided for the construction related modularity discussion (Antonio, Yam, and Tang 2007; Björnfot and Stehn 2007; Goodier and Gibb 2007; Nadim and Goulding 2010; Pan, Gibb, and Dainty 2007; Pandremenos et al. 2009; Pasquire and Connolly 2002; Voordijk, Meijboom, and de Haan 2006) by providing a practical example of how the construction related technical portfolio can be formed by using the product structure concept. The technical product/service portfolio is modular.

The role of productisation is further clarified by providing an example in the construction industry context on modelling products/services as commercial and technical portfolios. This study, hence, supports Harkonen, Tolonen, and Haapasalo (2017; 2018), Tolonen, Harkonen, and Haapsalo (2014), Tolonen et al. (2018), and Tolonen (2016). The understanding on product/service product structure and the focus of productisation by (Harkonen, Tolonen, and Haapasalo 2018; Tolonen et al. 2018) is further supported. Jaakkola (2011) is also supported by providing new understanding of the role of productisation in respect to modelling products/services and the focus of productisation. Harkonen, Tolonen, and Haapasalo (2017) is also complemented by providing an example in the construction industry context. Tolonen, Harkonen, and Haapsalo (2014), and Tolonen (2016) are complemented by providing another ex- 
ample in the context of portfolio thinking. Cooper, Edgett, and Kleinschmidt (1997) is supported by providing a practical example of a frame in the construction industry context to support prod$\mathrm{uct} /$ service portfolio management to enable monitoring and reacting to the behaviour of products and services in the markets and within the company.

\section{MANAGERIAL IMPLICATIONS}

The managerial implications of the study include providing an example of how the product structure concept can be applied, and how manufacturing offering can be modelled and productised as a product or as a service as commercial and technical portfolios. The importance of modelling construction offering is emphasised to allow effective productisation. Construction managers' understanding on the significance of commercial and technical portfolios is also supported. The study provides a simple example of how the configurability and the modularity of construction offering can be ensured in a manageable fashion. The life-cycle considerations along the construction portfolio are also supported. Managers can benefits of the provided frame and logic for productising construction products and services. Overall, a simple frame is provided to support maximising the effectiveness of construction activities.

\section{LIMITATIONS AND FUTURE STUDIES}

The limitations of this study include modelling of construction products and services along the product structure concept and commercial and technical portfolios by utilising publicly available material, and not confirming the findings with construction professionals or obtaining their feedback. Only one simple example is provided that can, however, be utilised by construction or any other professionals in their fields. Also, more real estate search engines could have been included in the analysis, but it is questionable whether they would have added any further value. Analysed constructors' descriptions on method of construction are also limited to building of reinforced concrete frame apartment buildings, whereas the technical portfolio might look somewhat different should other types of buildings be modelled. Naturally there are possibilities of modelling slightly differently as commercial and technical portfolios, while the main principle remains the same. The future studies can involve addressing the limitations of this study. Also, future studies can involve analysing pricing and costing products and services in the portfolio context, and further analysing the performance management and

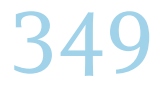


key performance indices in the context of commercial and technical portfolios and productisation. Further analysing product structure concept, productisation, and commercial and technical portfolios in the building information modelling context might prove an interesting topic for a future study.

\section{References}

Antonio, K. W. L., R. C. M. Yam, and E. Tang. 2007. 'The Impacts of Products Modularity on Competitive Capabilities and Performance: An Empirical Study.' International Journal of Production Economics 105:1-20.

Azhar, S., A. Nadeem, J. Y. N. Mok, and B. Y. H. Leung. 2008 `Building Information Modeling (вІм): A New Paradigm for Visual Interactive Modeling and Simulation for Construction Projects.' Paper presented at the First International Conference on Construction in Developing Countries, Karachi, 4-5 August.

Björk, B. C. 1989. 'Basic Structure of a Proposed Building Product Model.' Computer-Aided Design 21 (2): 71-8.

Björnfot, A., and L. Stehn. 2007. 'A Design Structural Matrix Approach Displaying Structural and Assembly Requirements in Construction: A Timber Case Study.' Journal of Engineering Design 18 (2): 113-24.

Boton, C., L. Rivest, D. Forgues, and J. Jupp. 2016. 'Comparing PLM and вIм from the Product Structure Standpoint.' Paper presented at the 13th IFIP WG 5.1 International Conference, Columbia, 11-13 July.

Cerovsek, T. 2011. 'A Review and Outlook for a "Building Information Model (вім):" A Multi-Standpoint Framework for Technological Development.' Advanced Engineering Informatics 25 (2): 224-44.

Cooper, R. G., S. J. Edgett, E. J. Kleinschmidt. 1997. 'Portfolio Management in New Product Development: Lessons from the Leaders 2.' Research Technology Management 40 (6): 43-52.

Eastman, C. 1976. 'General Purpose Building Description Systems.' Computer Aided Design 8 (1): 17-26.

Eastman, C. M., and A. Siabiris. 1995. 'A Generic Building Product Model Incorporating Building Type Information.' Automation in Construction 3 (4): 283-304.

Gann, D. M. 1996. 'Construction as a Manufacturing Process? Similarities and Differences between Industrialized Housing and Car Production in Japan.' Construction Management \& Economics 14 (5): 43750.

Goodier, C., and A. Gibb. 2007. 'Future Opportunities for Offsite in the uk.' Construction Management and Economics 25 (6): 585-95.

Harkonen, J., H. Haapasalo, and K. Hanninen. 2015. 'Productisation: A Review and Research Agenda.' International Journal of Production Economics 164:65-82. 
Harkonen, J., A. Tolonen, H. Haapasalo. 2017. 'Service Productisation: Systematising and Defining an Offering.' Journal of Service Management 28 (5): 936-71.

Harkonen, J., A. Tolonen, and H. Haapasalo. 2018. 'Modelling of Manufacturing Services and Processes for Effective Productisation.' Paper presented at the 2oth International Working Seminar on Production Economics, Innsbruck, 19-23 February.

Hvam, L., N. H. Mortensen, and J. Riis. 2008. Product Customization. Berlin: Springer.

Jaakkola, E. 2011. 'Unraveling the Practices of "Productization" in Professional Service Firms.' Scandinavian Journal of Management 27 (2): 221-30.

Jensen, P., T. Olofsson, and H. Johnsson. 2012. 'Configuration through the Parameterization of Building Components.' Journal of Automation in Construction 23:1-8.

Jensen, P., H. Lidelöw, and T. Olofsson. 2015. 'Product Configuration in Construction.' International Journal of Mass Customisation 5 (1): 7392.

Kokkonen, T. 2017. 'Business Case Sales Planning Concept for New Products and Product Portfolio.' Master's Thesis, University of Oulu, Oulu.

Krause, D., G. Beckmann, S. Eilmus, N. Gebhardt, H. Jonas, and R. Rettberg. 2014. 'Integrated Development of Modular Product Families: A Methods Toolkit.' In Advances in Product Family and Product Platform Design, edited by T. W. Simpson, J. R. Jiao, Z. Siddique, and K. Hölttä-Otto, 245-70. New York: Springer.

Kropsu-Vehkapera, H., and H. Haapasalo. 2011. 'Defining Product Data Views for Different Stakeholders.' The Journal of Computer Information Systems 52 (2): 61-72.

Maloney, W. F. 2002. 'Construction Product/Service and Customer Satisfaction.' Journal of Construction Engineering and Management 128 (6): 522-29.

Mustonen, E. (2017). Creation of The Common Commercial Product Portfolio by the Cluster of Companies, Master's Thesis, University of Oulu, Oulu.

Nadim, W., and J. Goulding. 2010. 'Offsite Production in the uk: The Way Forward?' Construction Innovation 10 (2): 181-202.

Olofsson, T., L. Stehn, and E. Cassel-Enqvist. 2004. 'Process and Information Flow in Mass Customisation of Multi-Story Housing.' Paper presented at the $5^{\text {th }}$ European Conference on Product and Process Modelling in the Building and Construction Industry, Istanbul, 8-10 September.

Orfi, N., J. Terpenny, and S. S. Asli. 2011. 'Harnessing Product Complexity: Step 1 - Establishing Product Complexity Dimensions and Indicators.' The Engineering Economist 56 (1): 59-79. 
Pan, W., A. Gibb, and A. Dainty. 2007. 'Perspectives of uk Housebuilders on the Use of Offsite Modern Methods of Construction.' Construction Management and Economics 25 (2): 183-94.

Pandremenos, J., J. Paralikas, K. Salonitis, and G. Chryssolouris. 2009. 'Modularity Concepts for the Automotive Industry.' cIRP Journal of Manufacturing Science and Technology 1 (3): 148-52.

Pasquire, C., and G. Connolly. 2002. 'Leaner Construction through OffSite Manufacturing.' Paper presented at the IGLC 10, Gramado, August.

Pavlic, D., M. Storga, N. Bojcetic, and D. Marjanovic. 2004. 'Generic Product Structure of the Configurable Product.' Paper presented at the International Design Conference, Dubrovnik, 18-21 May.

Peleskei, C. A., V. Dorca, R. A. Munteanu, and R. Munteanu. 2015. 'Risk Consideration and Cost Estimation in Construction Projects Using Monte Carlo Simulation.' Management 10 (2): 163-76.

Pinquié, R., L. Rivest, F. Segonds, and P. Veron. 2015. 'An Illustrated Glossary of Ambiguous PLM Terms Used in Discrete Manufacturing.' International Journal of Product Lifecycle Management 8 (2): 142-71.

Ripperda, S., and D. Krause. 2015. 'Cost Prognosis of Modular Product Structure Concepts.' Paper presented at the 2oth International Conference on Engineering Design, Milan, 27-30 July.

Tam, V. W. Y., C. M. Tam, S. X. Zeng, and W. C. Y. Ng. 2007. ‘Towards Adoption of Prefabrication in Construction.' Building and Environment 42 (10): 3642-54.

Taylor, M. D. 2010. 'A Definition and Valuation of the uk Offsite Construction Sector.' Construction Management and Economics 28 (8): 885-96.

Tolonen, A., J. Harkonen, and H. Haapasalo. 2014. 'Product Portfolio Management-Governance for Commercial and Technical Portfolios over Life Cycle.' Technology and Investment 5 (4): 173-83.

Tolonen, A. 2016. 'Product Portfolio Management over Horizontal and Vertical Portfolios.' Doctoral Thesis, Acta Universitatis Ouluensis, C Technica 574, University of Oulu, Oulu.

Tolonen, A., M. Shahmarichatghieh, J. Harkonen, and H. Haapasalo. 2015. 'Product Portfolio Management: Targets and Key Performance Indicators for Product Portfolio Renewal over Life Cycle.' International Journal of Production Economics 170 (в): 468-77.

Tolonen, A., J. Harkonen, H. Haapasalo, and H. Hannila. 2018. 'Performance Management of the Manufacturing Services Product Portfolio.' Paper presented at the 2oth International Working Seminar on Production Economics, Innsbruck, 19-23 February.

Valminen, K., and M. Toivonen. 2012. 'Seeking Efficiency through Productisation: A Case Study of Small ківs Participating in a Productisation Project.' Service Industries Journal 32 (2): 273-89. 
Voordijk, H., B. Meijboom, and J. de Haan. 2006. 'Modularity in Supply Chains: A Multiple Case Study in The Construction Industry.' International Journal of Operations \& Production Management 26 (6): 600-618.

Vukasovic, T., and J. Zidar. 2014. 'Introduction of New Products on the Market with Regards to the Internal Potential of the Company.' Management 9 (1): 33-48.

Vukasovic, T., and N. Mikulic. 2014. 'Product Offerings Testing through Customer Satisfaction.' Management 9 (3): 223-37. 